\title{
Pemetaan Klaster UMKM dalam Penguatan Pengembangan Ekonomi Lokal Menghadapi Pandemi Covid19 Studi Kasus Jangkauan Pelayanan Telekomunikasi di UMKM Makan Ringan Kabupaten Temanggung
}

\author{
Mapping of MSMEs Clusters in Strengthening Local Economic \\ Development toward Covid-19 Pandemic; Case Study of \\ Telecommunication Service Coverage at MSMEs Snacks in \\ Temanggung Regency
}

\section{Indra Hadi Wijaya ${ }^{1}$, Bagus Nuari Priambudi ${ }^{1}$, Nofa Martina Ariani ${ }^{1}$ dan Surya Tri Esthi Wira Hutama ${ }^{2}$}

\begin{abstract}
AbstraK: Pandemi COVID19 telah menunjukkan dampaknya terhadap perekonomian global terutama pelaku usaha dan sektor yang paling terdampak langsung adalah pelaku UMKM (Usaha Mikro Kecil dan Menengah). UMKM memiliki peranan yang vital karena dapat berimplikasi langsung dengan system pangan dan pergerakan ekonomi di lokal desa. Salah satunya yaitu UMKM olahan makanan ringan yang merupakan aktivitas usaha mengolah bahan baku (komoditas) menjadi produk makanan sampai tahap pemasaran, sehingga diharapkan UMKM makanan ringan mampu cepat beradaptasi dimasa pandemi mengingat makanan merupakan kebutuhan primer. Menghadapi kondisi tujuan dari penelitian ini untuk mengidentifikasi konsep adaptasi dan penyediaan pelayanan telekomunikasi bagi UMKM makanan ringan agar tetap dapat bertahan. Pendekatan kerangka kerja system pasar dari tahapan bahan baku, produksi/pengolahan hingga pemasaran dideskripsikan dalam pemetaan sebaran UMKM makanan ringan dalam penggunaan teknologi informasi dan komunikasi dan ketersediaan fasilitas komunikasi di Kabupaten Temanggung. Data penelitian ini bersumber dari data primer yang dikumpulkan dengan wawancara, kuesioner pelaku klaster UMKM dan sebaran jangkauan pelayanan telekomunikasi dari data program penyediaan fasilitas telekomunikasi pemerintah daerah di Kabupaten Temanggung. Hasil dari penelitian ini adalah pemetaan UMKM dan adaptasi pelaku usaha UMKM makanan ringan dalam menghadapi pandemic Covid 19 sebagian telah memanfaatkan teknologi informasi dan komunikasi baik melalui fasilitas pemerintah dan yang dilakukan secara mandiri.
\end{abstract}

Kata kunci: Infrastruktur, Klaster, UMKM

\begin{abstract}
The COVID19 pandemic has shown its impact on the global economy, especially business actors and the sectors most directly affected are MSME players (Micro, Small, and Medium Enterprises). MSMEs have a vital role because they can have direct implications for the food system and economic movements in local villages. One of them is SME processed snacks, which is a business
\end{abstract}

\footnotetext{
${ }^{1}$ Sekolah Vokasi Universitas Diponegoro

${ }^{2}$ Institut Teknologi Sumatra
} 
activity of processing raw materials (commodities) into food products up to the marketing stage, so it is hoped that snack MSMEs will be able to adapt quickly during the pandemic, considering that food is a primary need. Facing the condition, the objective of this research is to identify the concept of adaptation and provision of telecommunication services for snack SMEs so that they can survive. The market system framework approach from the stages of raw materials, production/processing to marketing is described in the mapping of the SME distribution of snacks in the use of information and communication technology and the availability of communication facilities in Temanggung Regency. The data of this research are sourced from primary data collected by interview, questionnaires of MSME cluster actors, and the distribution of telecommunication service coverage from the data of the local government telecommunication facility provision program in Temanggung Regency. The results of this study are the mapping of MSMEs and the adaptation of snack SME business actors in the face of the Covid 19 pandemic, some of which have utilized information and communication technology both through government facilities and which are carried out independently.

Keywords: Clusters, Infrastructure, MSME

\section{PENDAHULUAN}

Kemampuan membangun kembali perekonomian lokal menjadi krusial bagi pengambil kebijakan di level pemerintahan pusat maupun daerah serta masyarakat dalam memitigasi pandemic Covid 19 global. Laporan Organisation for Economic Co-operation and Development (OECD) menyebutkan bahwa pandemi ini berimplikasi terhadap ancaman krisis ekonomi besar yang ditandai dengan terhentinya aktivitas produksi di banyak negara, jatuhnya tingkat konsumsi masyarakat, hilangnya kepercayaan konsumen yang pada akhirnya mengarah kepada ketidakpastian (Brown \& Rocha, 2020). Kondisi ini sebagai akibat dari berhentinya proses investasi/jual beli dimana wirausahawan dan investor/pembeli tidak dapat secara fisik bertemu, berinteraksi, dan berkomunikasi dengan proses jual beli yang sangat berbasis jaringan, relasional, dan yang dimediasi secara spasial (Baker \& Bloom, 2020).

Indonesia yang didominasi oleh keberadaan Usaha Mikro, Kecil, dan Menengah (UMKM) sebagai tulang punggung perekonomian nasional juga terdampak secara serius tidak saja pada aspek total produksi dan nilai perdagangan akan tetapi juga pada jumlah tenaga kerja yang harus kehilangan pekerjaannya karena pandemi ini (Pakpahan, 2020). Data Kementerian Koperasi dan UKM RI bahwa secara jumlah unit, UMKM memiliki pangsa sekitar 99,99\% (62.9 juta unit) dari total keseluruhan pelaku usaha di Indonesia pada tahun 2017, sementara itu usaha besar hanya sebanyak 0,01\% atau sekitar 5400 unit. Usaha Mikro mampu menyerap sekitar 107,2juta tenaga kerja (89,2\%), sementara itu usaha Kecil 5,7 juta (4,74\%), dan jumlah usaha Menengah sebesar 3,73 juta (3,11\%). sementara untuk usaha Besar menyerap tenaga kerja sekitar 3,58 juta jiwa, dapat dimaknai bahwa secara gabungan jumlah UMKM di Indonesia menyerap sekitar 97\% tenaga kerja nasional (Kementerian Koperasi dan Usaha Kecil dan Menengah Republik Indonesia, 2019). Pada aspek UMKM, adanya pandemi ini menyebabkan turunnya kinerja dari sisi permintaan (konsumsi dan daya beli masyarakat) yang akhirnya berdampak pada sisi suplai yakni pemutusan hubungan kerja dan ancaman macetnya pembayaran kredit (Pakpahan, 2020).

Di Indonesia, usaha menengah kecil dan mikro sering terkonsentrasi di tingkat desa dan setidaknya sebagian tertanam dalam ikatan sosial yang kuat dan lembaga terkait budaya. Disisi lain konsentrasi ini di dilakukan oleh pelaku usaha karena faktor sumber bahan baku (Phelps \& Wijaya, 2016). UMKM memiliki peranan yang vital karena dapat berimplikasi langsung dengan system pangan dan pergerakan ekonomi di lokal desa. Covid di Indonesia yang mulai masuk ke wilayah pedesaan, pada bulan April ada sekitar 24.519 warga dalam kategori orang dalam pemantauan (ODP) yang tersebar di sejumlah desa di 17 provinsi, seperti di Provinsi Jawa Barat, 1.779 desa dengan 11.832 ODP, Riau 
168 desa dengan 8.988, NTB 67 desa dengan 891, dan Bali 208 desa dengan 501 (Agus, 2020).

Kabupaten Temanggung sebagai bagian dari wilayah Provinsi Jawa Tengah yang memiliki 266 desa memiliki potensi UMKM yang besar baik dari pariwisata dan sector pertanian (Wijaya, Tri, et al., 2020). UMKM di wilayah ini sedikit banyak mendapatkan dampak pandemi covid 19. Sektor pertanian yang merupakan sektor unggulan daerah juga mendapatkan dampak (Ulya, 2020). Pengolahan hasil pertanian di Kabupaten Temanggung yang sebagian besar dilakukan oleh UMKM yang tersebar di 20 kecamatan dituntut untuk beradaptasi di awal kebijakan penanganan covid. Salah satunya yaitu UMKM olahan makanan ringan yang merupakan aktivitas usaha mengolah bahan baku (komoditas) menjadi produk makanan sampai tahap pemasaran, sehingga diharapkan UMKM makanan ringan mampu cepat beradaptasi dimasa pandemi mengingat makanan merupakan kebutuhan primer.

Adaptasi pelaku UMKM makan ringan dilakukan dengan memanfaatkan TIK (Teknologi Informasi dan Komunikasi) dalam proses produksi dan pemasaran. Penggunaan TIK akan merubah paradigma yang bersifat fisik, sehingga ruang fisik perusahaan UMKM dan letak secara geografis tidak lagi hal yang signifikan. Pada UMKM, pemanfaatan TIK akan berdampak pada transparansi internal yang lebih besar, praktek berkoordinasi dan penggunaan pada eksternal yang lebih baik (Street \& Meister, 2004). Tantangan dalam pengembangan ini adalah penyediaan pelayanan telekomunikasi bagi UMKM makanan ringan agar tetap dapat bertahan, dengan pendekatan kerangka kerja system pasar dari tahapan bahan baku, produksi/pengolahan hingga pemasaran yang diidentifikasi. Melalui Dinas Komunikasi dan Informatika (Dinkominfo) Kabupaten Temanggung, fasilitas jaringan internet desa tersebut telah berhasil dipasang di 107 desa dari total 266 desa yang ada di Temanggung (Sutrisno, 2018).

Penguatan pengembangan ekonomi lokal menghadapi pandemi covid19 dari beberapa kajian yang telah dilakukan mendukung pelaku usaha menjadi alternatif dalam pemasaran dan penjualan, mengamankan modal dan aset, mengalihkan sementara untuk usaha lainnya, dan harus mempelajari teknologi yang dipandang efektif atau yang disebut dengan digital marketing (Shofiana, 2020; Soetjipto, 2020; Hardilawati, 2020). Beberapa penelitian yang telah dilakukan belum banyak membahas terkait dengan sebaran UMKM secara spasial, dimana lokasi UMKM di wilayah perkotaan dan pedesaan. Penelitian ini melakukan identifikasi melalui pemetaan sebaran dan jangkauan pelayanan pada UMKM Makanan Ringan di Kabupaten Temanggung sebagai respon terhadap kondisi pandemic covid 19, dan adanya potensi lokal yang tinggi dan mayoritas masyarakatnya masih memiliki usaha berskala mikro dan kecil. Keterkaitan pemetaan UMKM dan pemetaan jangkauan pelayanan telekomunikasi dalam menumbuhkan penguatan ekonomi lokal yang memiliki kemampuan untuk beradaptasi di era pandemi COVID19. Kesiap-siagaan pemerintah dengan penyediaan sarana dan prasarana pendukung kegiatan UMKM melalui pengembangan TIK akan menjadi tantangan kedepannya.

\section{METODE}

Penelitian pemetaan klaster UMKM dalam penguatan pengembangan ekonomi lokal menghadapi pandemi covid19 dengan studi kasus jangkauan pelayanan telekomuikasi di UMKM makan ringan Kabupaten Temanggung menggunakan dilakukan pada penelitian ini antara lain meliputi metode pengumpulan data, metode analisis, metode pelaksanaan. Pendekatan yang dilakukan dalam penelitian ini adalah pendekatan spasial yang menggambarkan kondisi nyata di lapangan. Pengumpulan data bersumber dari data primer yang dikumpulkan dengan wawancara kepada tokoh kunci (pemerintah dan pelaku usaha), kuesioner dengan purposive sampling pelaku klaster UMKM di setiap desa di Kabupaten Temanggung. Data terkait sebaran jangkauan pelayanan telekomunikasi dari 
data program penyediaan jaringan telekomunikasi Pemerintah Daerah Kabupaten Temanggung dilakukan berdasarkan data sekunder.

Metode analisis yang digunakan dalam penelitian ini adalah deskriptif spasial dimulai dengan analisis spasial dengan pemetaan sebaran UMKM Makanan Ringan dan pemetaan sebaran penggunaan TIK yang dilakukan UMKM di setiap desa di Kabupaten Temanggung. Pemetaan penggunaan TIK dilakukan dari proses produksi dan pemasaran UMKM. Hasil dari pemetaan lokasi UMKM dan variable penggunaan TIK di overlay dengan data sebaran infrastruktur telekomunikasi dari program pemerintah Kabupaten Temanggung. Setelah proses tersebut dilakukan maka akan diketahui UMKM yang memanfaatkan fasilitas telekomunikasi dan UMKM yang berdikari/mandiri dalam penyediaan telekomunikasi dalam proses adaptasi covid 19. Hasil dari kedua deskripsi spasial dilakukan analisis deskriptif kuantitatif keterkaitan peran infrastruktur dari hasil wawancara dan kuesioner dalam proses adaptasi dalam menghadapi Covid19 di UMKM Makanan Ringan di Kabupaten Temanggung.

\section{HASIL DAN PEMBAHASAN}

\section{Identifikasi Sebaran Umkm Makanan Ringan}

Salah satu produk unggulan di Kabupaten Temanggung sebagai kabupaten dengan potensi di sektor pertanian adalah produk pengolahan makanan ringan. Beberapa contoh produk yang terkait pengolahan makanan ringan adalah olahan talas, singkong, pisang, jagung, buah, kacang, sayur, hewan, beras, minuman. Produk yang dihasilkan kue kering, kue basah, dan olahan lain-lain (Gambar 1) menunjukkan jumlah usaha dan tenaga kerja yang bekerja pada produk pengolahan makanan ringan di Kabupaten Temanggung. Pada tahun 2019, jumlah usaha terkait produk pengolahan makanan ringan telah mencapai 1.775 usaha dengan memberdayakan tenaga kerja mencapai 6.041 tenaga kerja yang tersebar di seluruh kecamatan di Kabupaten Temanggung.

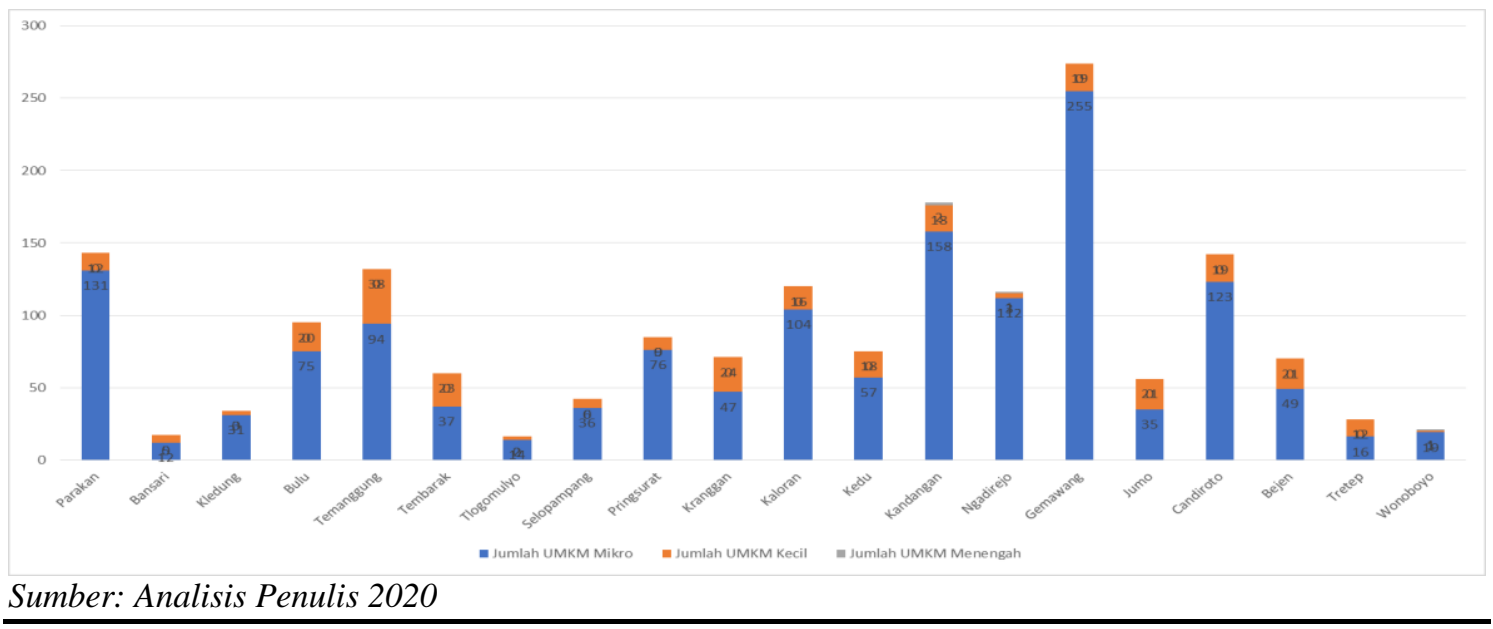

\section{Gambar 1. Jumlah Pelaku Usaha UMKM di Kabupaten Temanggung}

Identifikasi pola spasial penyebaran pelaku usaha produk makanan ringan di Kabuapten Temanggung (Gambar 2) jika dilihat dari pola spasialnya banyak pelaku usaha berkembang di daerah pedesaan dan sebagian kecil di Kawasan perkotaan. Sedangkan untuk wilayah yang merupakan kawasan pertkotaan seperti Kecamatan Temanggung dan 
Parakan jumlah pelaku usaha produk makanan ringan relatif lebih sedikit. Identifikasi produk bahan baku usaha makanan ringan oleh (S. T. . Hutama et al., 2020), persebaran UMKM yang menggunakan bahan baku lokal sebagai bahan baku untuk produksi makanan ringan seperti olaha tepung dan singkong terdapat pada beberapa desa yang berada di kecamatan Candiroto, Gemawang, Kandangan dan Kaloran. Persebaran UMKM yang menggunakan bahan baku lokal cenderung memiliki kesamaan pola dengan persebaran UMKM dikarenakan jumlah dari UMKM yang menggunakan bahan baku lokal merupakan mayoritas dari keseluruhan UMKM.

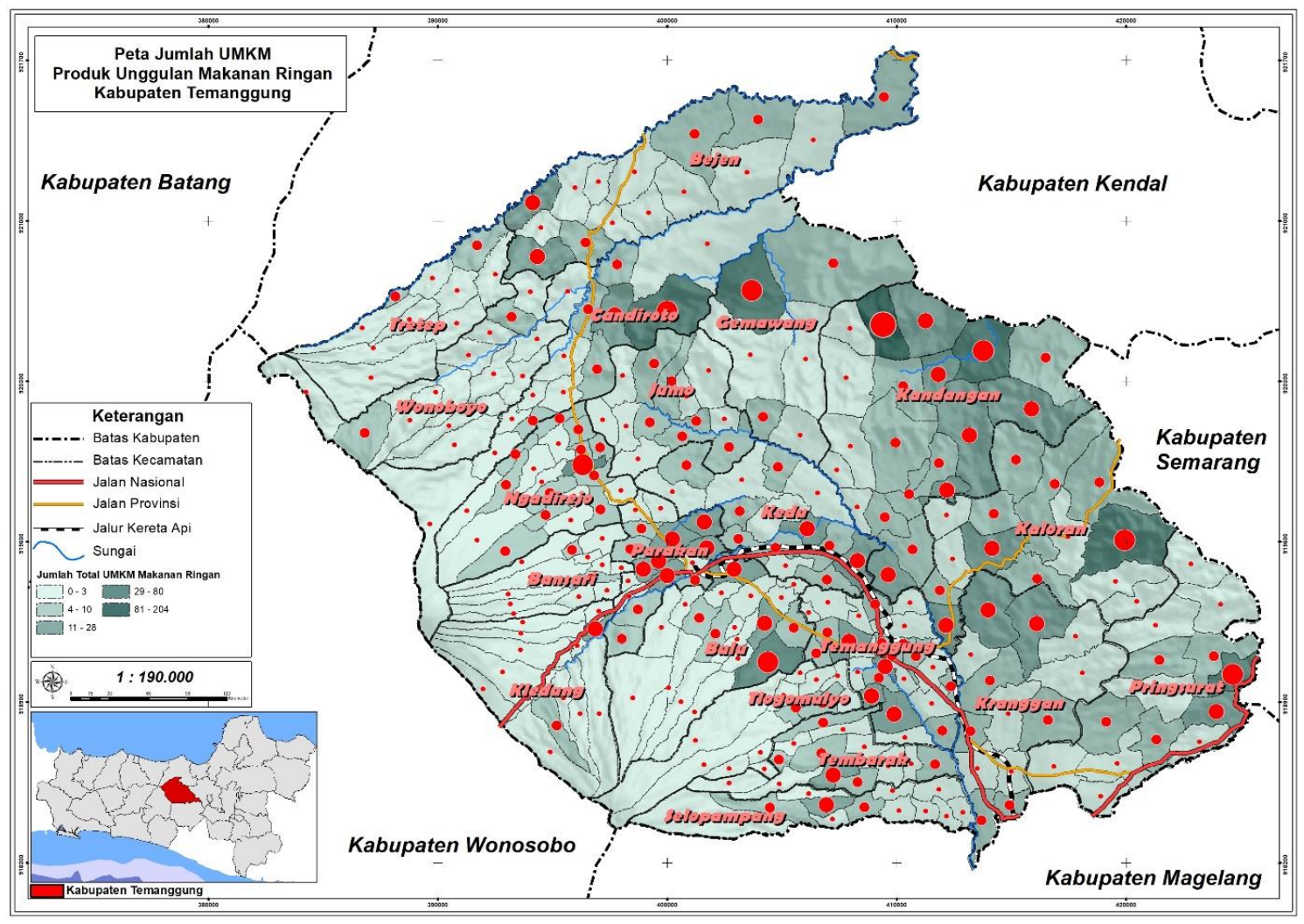

Analisis Penulis 2020

\section{Gambar 2 Peta Persebaran UMKM Produk Makanan Ringan Kabupaten Temanggung}

\section{Penggunaaan TIK dalam Proses Produksi dan Pemasaran}

Kondisi pandemi covid 19 baik lokal maupun internasional mengalami mengakibatkan global society shock yang salah satu dampak terbesar adalah performa dan produktivas UMKM, salah satu strategi untuk mengembalikan posisi UMKM dengan teknologi digital (Papadopoulos et al., 2020). Penggunaan teknologi di UMKM di Kabupaten Temanggung yang berhasil di identifikasi adalah kegiatan pemasaran yang bagian dari komponen rantai produksi agar tetap berjalan tetap berjalan. Persentase menunjukkan hanya $6,6 \%$ dari para pelaku usaha UMKM makanan ringan yang menggunakan internet sebagai media untuk pemasaran produk. Penggunaan teknologi informasi dan komunikasi dalam proses pemasaran diidentifikasi berbentuk pemasaran menggunakan e-commerce, social media dan aplikasi pesan (whatsapp). 
Hasil identifikasi secara spasial (Gambar 3) penggunaan media digital/teknologi komunikasi dalam proses pemasaran hasil UMKM paling besar ada di wilayah perkotaan dan terdapat temuan ada beberapa daerah pedesaan dimana UMKM mampu mengakases pemasaran menggunakan teknologi informasi dan komunikasi. Indikasi faktor pertumbuhan penduduk yang berkelanjutan di daerah pedesaan, baik dari pendatang baru yang tertarik dengan potensi pedesaan maupun oleh para migran yang kembali, menjanjikan peningkatan keterampilan yang dibutuhkan untuk ekonomi baru dengan pemanfaatan teknologi (Malecki, 2003). Pelaku usaha yang menggunakan teknologi informasi dalam proses pemasaran mendapatkan alih pengetahuan dari stakeholder luar.

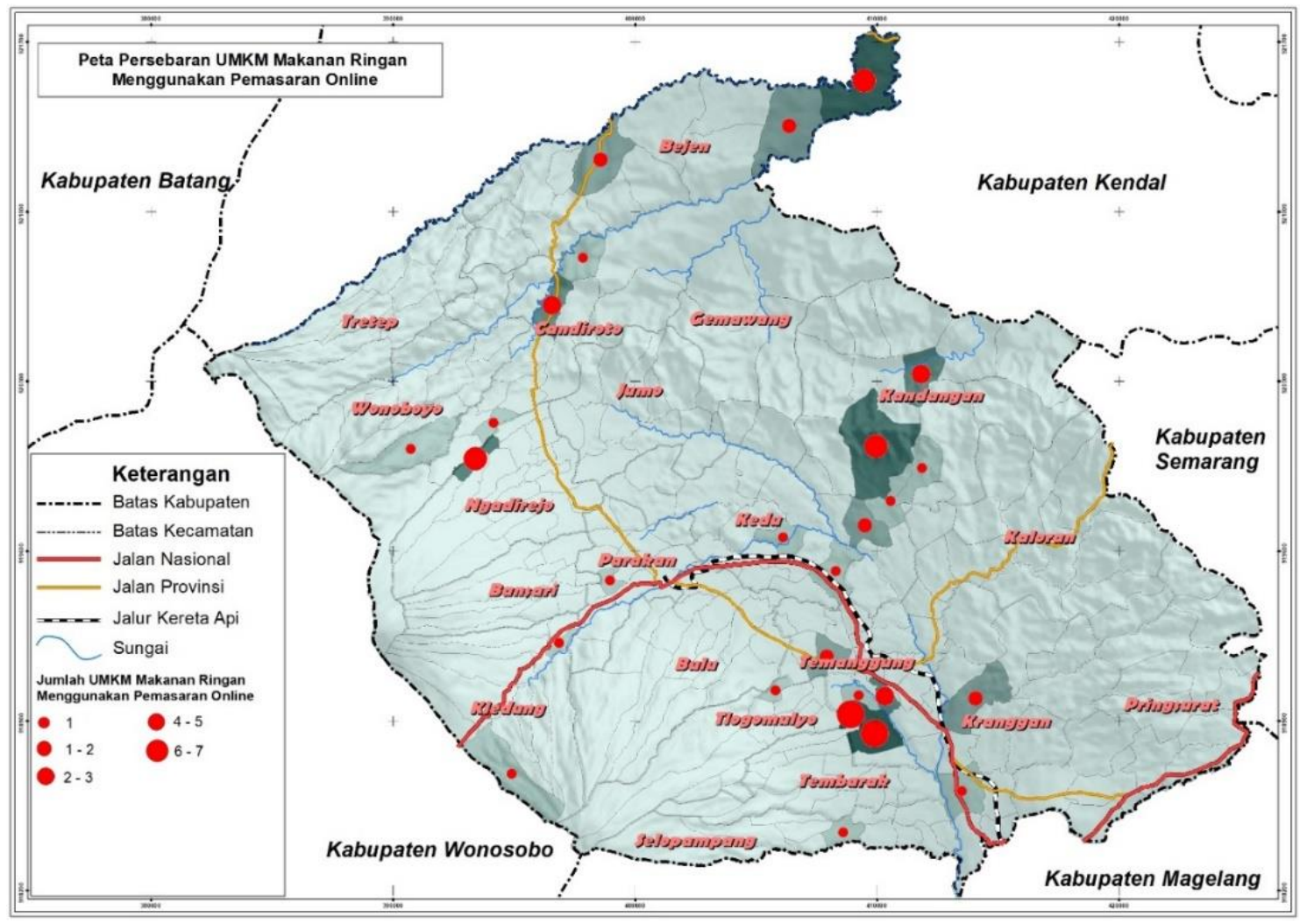

Analisis Penulis 2020

Gambar 3 Peta Persebaran Pelaku Usaha Olahan Makanan Aktif Memasarkan Secara Online

\section{Identifikasi Sebaran Infrastruktur Telekomunikasi}

Akses teknologi informasi dan komunikasi menjadi alat pembangunan vital dan telah menjadi salah satu indikator kemajuan suatu wilayah (Nurilah, 2014). Kabupaten Temanggung sebagian besar adalah wilayah pedesaan menjadi tantangan dalam mengases teknologi informasi dan komunikasi. Hasil dari survey Akses Teknologi Informasi dan Komunikasi Kabupaten Temanggung tahun 2018 penggunaan TIK khususnya terkait dengan akses rumah tangga terhadap TIK dan penggunaan perangkat TIK oleh individu.

Penggunaan internet sebagai bagian dari penggunaan TIK dalam kegiatan mengindikasikan 66,7\% masyarakat telah menggunakan internet dalam 3 bulan terkahir, sisanya tidak memiliki akses terhadap penggunaan internet. Hasil lain sepertiga penduduk 
5 tahun keatas telah menggunakan internet 3 bulan terakhir dan media paling dominan digunakan adalah smartphone sebanyak 89,4 persen (Informasi, 2018).

Hasil identifikasi data sekunder untuk UMKM dapat diasumsikan dalam penggunaan teknologi informasi dan komunikasi di sektor PDRB, UMKM makanan ringan yang masuk dalam sektor penyedia akomodasi dan penyediaan makanan minum memiliki 58,2\% pelaku usaha dengan rentang umur 16-65. Sedangkan di industri pengolahan penggunaan TIK di rentang umur 16-65 memiliki presentase pengguna 39,8\%. Kondisi ini mengindikasikan UMKM Makanan Ringan yang masuk dalam sektor penyumbang PDRB sudah melakukan aktivitas menggunakan TIK (Informasi, 2018).

Peran pemerintah dalam penyediaan layanan teknologi informasi dan komunikasi, khususnya untuk pengembangan pedesaan telah memberikan fasilitas infrastruktur telekomunikasi dan internet ke desa. Dari 288 desa dan kelurahan di Kabupaten Temanggung 199 desa telah difasilitasi infrastruktur telekomunikasi internet mulai tahun 2015 hingga 2020. Fasilitas infrastruktur telekomunikasi dan internet ini dapat digunakan untuk promosi/pemasaran hasil usaha lokal. Hasil identifikasi dan olah data dapat dilihat di (Gambar 4) adalah sebaran Desa yang memiliki jaringan internet.

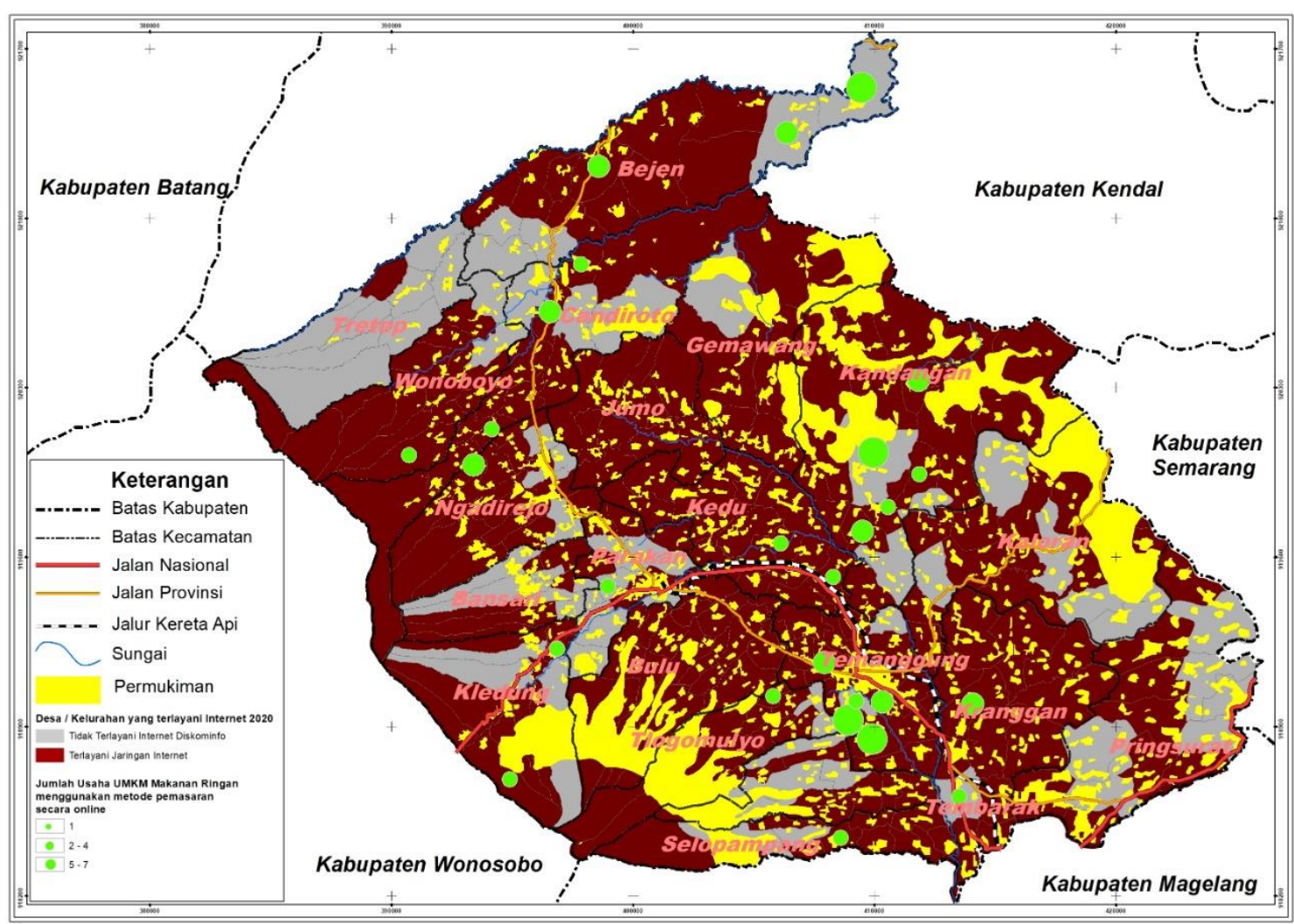

Analisis Penulis 2020

\section{Gambar 4 Peta Sebaran Infrastruktur Pelayanan Internet Diskominfo}

\section{Proses Adaptasi UMKM dalam Pandemi Covid}

Pembatasan kegiatan sebagai dampak dari pandemi Covid-19 yang dirasakan oleh UMKM khususnya UMKM Makanan Ringan di Kabupaten Temanggung menjadikan aktivitas produksi dan pemasaran mengalami hambatan. Kriteria adaptasi disampaikan oleh (S. T. E. W. Hutama et al., 2020) terdapat 3 kriteria, kriteria pertama adalah 
penyediaan bahan baku dimana UMKM makanan ringan di Kabupaten Temanggung menggunakan bahan baku lokal yang mudah didapat dan memberikan nilai tambah dalam rantai nilai usaha. Sebagai contoh UMKM yang berkembang dari produk pertanian lokal adalah usaha kopi dan tembakau. Bahan baku kopi yang tersebar merata di seluruh wilayah Kabupaten Temanggung, di dataran tinggi terdapat kopi arabika dan untuk di dataran rendah terdapat kopi robusta. Sedangkan tembakau banyak tersebar di wilayah Gunung Sumbing dan Sindoro dengan komoditas yang dihasilkan untuk produk UMKM adalah tembakau lembutan yang digunakan untuk rokok lintingan. Kriteria kedua adalah kesesuaian produk UMKM makanan ringan dengan kebutuhan pasar saat Pandemi Covid 19. Dimana hasil produksi makanan dapat meningkatkan imun tubuh dengan bahan baku sayur-sayuran dan rempah-rempah. Kriteria terakhir adalah hilirisasi dari proses dengan pemanfaatan teknologi seperti disebutkan di atas bahwa beberapa pelaku usaha dengan kriteria produk yang sesuai dengan kondisi pandemic telah menggunakan internet sebagai media pemasaran.

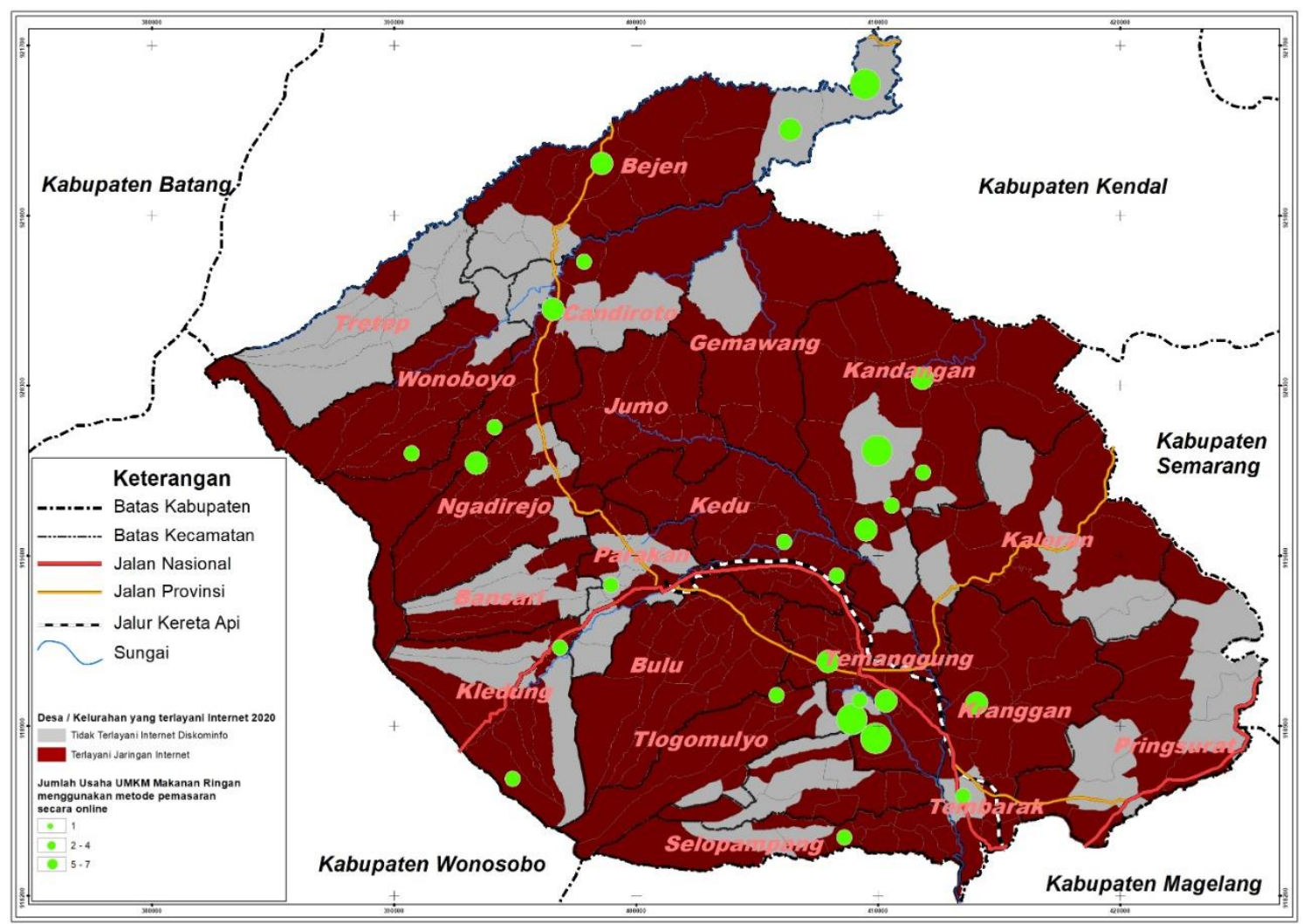

Analisis Penulis 2020

\section{Gambar 5 Peta Sebaran Pelaku Usaha/UMKM yang Menggunakan Internet dalam Proses Pemasaran}

Hasil identifikasi dari survey dan data sekunder memperlihatkan 6,6\% pelaku usaha makanan ringan telah melakukan pemasaran memanfaatkan teknologi informasi dan komunikasi seperti internet dalam proses pemasaran (Gambar 5). Sebagian besar dari pelaku berada di Kawasan perkotaan tetapi dikawasan pedesaan juga terdapat UMKM yang memanfaatkan TIK. Penggunaan teknologi informasi di wilayah Kabupaten Temanggung dinilai telah mampu mengurangi biaya dan meningkatkan tingkat layanan 
kepada pelangan sesuai dengan Kumar \& Petersen, (2006) terkait dengan dampak ecommerce terhadap biaya produksi barang. Chiu et al., (2006) menilai kemajuan pesat dalam teknologi informasi dan komunikasi cenderung berkembang tautan virtual antara UMKM, di Kabupaten Temanggung penggunaan teknologi berkontribusi untuk mewujudkan hubungan kolaboratif dengan mitra dagang dan memudahkan proses manufaktur virtual.

\section{DISKUSI}

Pemetaan UMKM makanan ringan di Kabupaten Temanggung dalam penggunaan TIK menghadapi pandemic Covid 19 telah dilakukan oleh sedikit pelaku usaha. Dari beberapa penelitian yang dilakukan (Shofiana, 2020; Soetjipto, 2020; Hardilawati, 2020) terkait penggunaan TIK dengan digital marketing sebgaai alternatif yang efektif di masa pandemi terbukti bermanfaat di wilayah studi. Temuan lain terkait dengan sektor pertanian yang terdampak besar dalam pandemi Ulya, (2020) juga dirasakan di wilayah Kabupaten Temanggung yang sebagian besar pendapatan daerah dari sektor ini. Yang menjadi menarik dalam sektor ini adalah pekerja di sektor pertanian mampu mengolah hasil pertanian ke barang setengah jadi atau barang jadi, sebagai contoh komoditas kopi tidak dijual mentah tetapi diolah menjadi produk jadi (kopi bubuk) yang secara tidak langsung menambah nilai jual dan memperpanjang rantai nilai akan memberikan kemanfaatan wilayah (Phelps \& Wijaya, 2016; Wijaya, Ariani, et al., 2020).

Secara spasial atau keruangan dimana penelitian-penelitian lain belum banyak membahasnya, terdapat beberapa temuan seperti terdapat UMKM di wilayah yang tidak memiliki program jaringan internet mampu berkembang secara mandiri dalam pemasaran menggunakan internet. Dimana kondisi ini membuktikan proses adaptasi masayarakat di wilayah mampu mengatasi kondisi ketidakpastian dengan pematasan interaksi dalam proses jual beli (Brown \& Rocha, 2020; Baker \& Bloom, 2020).

\section{KESIMPULAN}

Pendekatan pemetaan UMKM dan jangkauan pelayanan telekomunikasi dalam menumbuhkan penguatan ekonomi lokal yang memiliki kemampuan untuk beradaptasi di era pandemi COVID-19 di Kabupaten Temanggung menghasilkan dua tipe pelaku usaha yang mampu bertahan diidentifikasi dari penggunaan TIK dan sebaran keruangan pelaku UMKM makanan ringan. Pertama adalah pelaku usaha yang berada wilayah pedesaan memiliki infrastruktur telekomonukasi/internet yang menggunakan fasilitas tersebut untuk pemasaran hasil produksi. UMKM tipe ini ini secara keruangan tersebar di Kawasan perkotaan dengan jangkauan fasilitas telekomunikasi yang memadai. Tipe kedua adalah pelaku usaha yang di wilayah desanya belum terlayani program infrastruktur telekomunikasi/internet dari pemerintah namun mampu menggunakan TIK untuk beradaptasi dengan memasarkan hasil produksi menggunakan pemasaran online. Sebagian besar pelaku di tipe kedua ini mendapatkan alih informasi dan teknologi dari luar, alih informasi dan teknologi seperti ini biasanya dibawa oleh konsumen.

Kedua temuan ini mengindikasikan bahwa inovasi pelaku usaha dalam menghadapi pandemi Covid 19 telah dilakukan oleh sedikit pelaku UMKM Makanan Ringan di Kabupaten Temanggung. Pelaku UMKM yang telah melakukan inovasi ini memiliki pasar yang lebih luas tidak hanya lokal. Sebagai contoh pelaku usaha kopi dan tembakau yang produknya sudah mencapai nasional dan internasional. Secara teoritis rantai usaha pemenuhan dan pemanfaatan infrastruktur telekomunikasi menjadi faktor pendorong UMKM dan menjadi factor eksternal dalam bertahan dan berkembang di masa pandemi Covid 19 terutama dalam pemasaran produk UMKM.

Peluang untuk penelitian lanjutan adalah identifikasi bagaimana peran kelembagaan UMKM makanan ringan berkembang dari wirausaha yang berorientasi keuntungan 
menjadi kewirausahaan berorientasi kemanfaatan sosial atau kewirausahaan sosial. Implementasi konsep ini menaraik untuk di teliti melihat bagaimana perekonomian, kondisi sosial dan kondisi lingkungan dibahas dalam bentuk pelaku usaha UMKM.

\section{PERNYATAAN RESMI}

Data dalam laporan ini sebagaian besar merupakan data Kegiatan Kajian Pemetaan Pengembangan Ekonomi Lokal Kabupaten Temanggung yang dilakukan oleh Pusat Pelayanan Perencanaan Pembangunan Partisipatif Fakultas Teknik Universitas Diponegoro dengan Bappeda Kabupaten Temanggung.

\section{DAFTAR PUSTAKA}

Agus, W. (2020). Lebih dari 40 Ribu Desa Bentuk Relawan Desa Lawan COVID-19. https://covid19.go.id/p/berita/lebih-dari-40-ribu-desa-bentuk-relawan-desa-lawan-covid-19

Baker, S. R., \& Bloom, N. (2020). Covid-Induced Economic Uncertainty. Journal of Chemical Information and Modeling, 53(9), 1689-1699.

Brown, R., \& Rocha, A. (2020). Entrepreneurial uncertainty during the Covid-19 crisis: Mapping the temporal dynamics of entrepreneurial finance. Journal of Business Venturing Insights, 14(April), e00174. https://doi.org/10.1016/j.jbvi.2020.e00174

Chiu, C. M., Hsu, M. H., \& Wang, E. T. G. (2006). Understanding knowledge sharing in virtual communities: An integration of social capital and social cognitive theories. Decision Support Systems, 42(3), 1872-1888. https://doi.org/10.1016/j.dss.2006.04.001

Hardilawati, W. laura. (2020). Strategi Bertahan UMKM di Tengah Pandemi Covid-19. Jurnal Akuntansi Dan Ekonomika, 10(1), 89-98. https://doi.org/10.37859/jae.v10i1.1934

Hutama, S. T. ., Wijaya, M. I. H., \& Puspasari, D. A. (2020). Tantangan dan Peluang Pemanfaatan ICT dalam Pemasaran Produk Klaster UMKM di Kabupaten Temanggung. 1(November), 18-26.

Hutama, S. T. E. W., Wijaya, M. I. H., Pramitasari, A., \& Purnama, A. G. (2020). Rekomendasi Lokasi Shelter Karantina Mandiri Sebagai Upaya Mitigasi Penyebaran Covid 19 Pada Permukiman Padat di Pesisir Utara Kota Semarang. Jurnal RIPTEK, 4(1), 23-33.

Informasi, A. T. (2018). Buku Infografis Survei Akses Teknologi Informasi dan Komunikasi (TIK) Kabupaten Temanggung.

Kementerian Koperasi dan Usaha Kecil dan Menengah Republik Indonesia. (2019). Arah Kebijakan Dan Program Pengembangan KUMKM (Menuju KUMKM 2020-2024). 1-36. http://www.depkop.go.id/uploads/news/1564979879_Arah Kebijakan dan Program Pengembangan KUMKM (Menuju KUMKM 2020-2024).pdf

Kumar, S., \& Petersen, P. (2006). Impact of e-commerce in lowering operational costs and raising customer satisfaction. Journal of Manufacturing Technology Management. $17 . \quad 283-302$. $10.1108 / 17410380610648263$.

Malecki, E. J. (2003). Digital development in rural areas: Potentials and pitfalls. Journal of Rural Studies, 19, 201-214. https://doi.org/10.1016/S0743-0167(02)00068-2

Nurilah. (2014). Pengaruh Komptensi Sumber Daya Manusia, Penerapan Sistem Akuntansi Pemanfaatan Teknologi Informasi , ( Studi Empiris Pada SKPD Kota Depok ). JOM FEKON Universitas Diponegoro.

Pakpahan, A. K. (2020). Covid-19 Dan Implikasi Bagi Usaha Mikro, Kecil, Dan Menengah. Jurnal Ilmiah Hubungan Internasional, $0(0)$, 59-64. https://doi.org/10.26593/jihi.v0i0.3870.59-64

Papadopoulos, T., Baltas, K. N., \& Balta, M. E. (2020). The use of digital technologies by small and medium enterprises during COVID-19: Implications for theory and practice. International Journal of Information Management, June, 102192. https://doi.org/10.1016/j.ijinfomgt.2020.102192

Phelps, N. A., \& Wijaya, H. B. (2016). Joint action in action? Local economic development forums and industry cluster development in Central Java, Indonesia. International Development Planning Review, 38(4), 425448. https://doi.org/10.3828/idpr.2016.24

Shofiana, A. (2020). Implementasi Program Afiliasi Berbasis Virtual Team Dalam Umkm Sebagai Upaya Peningkatan Perekonomian Pada Masa Pandemi Covid-19 (Implementation of Virtual Team-Based Affiliation Programs in MSMEs as Efforts for Increasing the Economy in the COVID-19 Pand. SSRN Electronic Journal. https://doi.org/10.2139/ssrn.3590822

Soetjipto, N. (2020). Ketahanan UMKM Jawa Timur Melintasi Pandemi COVID-19. In K-Media. 
Street, C. T., \& Meister, D. B. (2004). Small business growth and internal transparency: The role of information systems. MIS Quarterly: Management Information Systems, 28(3), 473-506. https://doi.org/10.2307/25148647

Sutrisno. (2018). Ratusan Desa di Temanggung telah Terfasilitasi Internet. https://kominfo.temanggungkab.go.id/home/berita/271/ratusan-desa-di-temanggung-telahterfasilitasi-internet-

Ulya, H. N. (2020). Alternatif Strategi Penanganan Dampak Ekonomi Covid-19 Pemerintah Daerah Jawa Timur Pada Kawasan Agropolitan. El-Barka: Journal of Islamic Economics and Business, 3(1), 80-109. https://doi.org/10.21154/elbarka.v3i1.2018

Wijaya, M. I. H., Ariani, N. M., \& Priambudi, B. N. (2020). Identifikasi Peran Kewilayahan Dalam Pengembangan Produk Unggulan Batik Di Kawasan Pekalongan. 4(2), 112-122. https://jurnal.pekalongankab.go.id/index.php/jurnalkabpekalongan/article/view/99/50

Wijaya, M. I. H., Tri, S., Wira, E., \& Laksita, Z. (2020). Peran Kelembagaan dalam Faktor Penarik Pariwisata Kabupaten Temanggung.

1(November)

27-35. https://jurnalbhumiphala.temanggungkab.go.id/index.php/bhumiphala/article/view/18 